\title{
As crianças e suas performances em contextos de instalações de jogo: diálogos entre Educação Infantil e Arte Contemporânea
}

\author{
Children and their performances in contexts of play facilities: dialogues \\ between Early Childhood Education and Contemporary Art
}

\section{Los niños y sus actuaciones en contextos de instalaciones de juego: diálogos entre Educación Infantil y Arte Contemporáneo}

\author{
Nathalia Scheuermann dos Santos 1 \\ https://orcid.org/0000-0002-7007-3104 \\ Rodrigo Saballa de Carvalho²
}

https://orcid.org/0000-0002-8899-0998

Resumo: A partir dos Estudos Sociais da Infância, em articulação com as contribuições dos estudos da Arte Contemporânea, o artigo tem como objetivo discutir a proposição de instalações de jogo na Educação Infantil, como contextos de produção de performances pelas crianças através de suas interações e brincadeiras. Por conseguinte, também apresenta indicativos para a criação de propostas de instalações de jogo, inspiradas em produções de arte contemporânea. Metodologicamente o artigo é constituído por três etapas. Na primeira etapa é apresentada uma revisão bibliográfica sobre a temática. Na segunda, é compartilhado um inventário de instalações produzidas por artistas contemporâneos. Por fim, na terceira etapa, são apresentadas análises de episódios de brincadeira vivenciados por crianças durante seções de instalações de jogo. A partir das análises, é possível inferir sobre a importância das instalações de jogo como espaço de produção de brincadeiras e performances pelas crianças.

Palavras-chave: Educação Infantil. Arte Contemporânea. Performance.

Abstract: From the Social Studies of Childhood, in conjunction with the contributions of Contemporary Art studies, the article aims to discuss the proposition of play facilities in Early Childhood Education, as contexts for the production of performances by children through their interactions and games. Consequently, also presents

\footnotetext{
' Mestranda em Educação no PPGEDU da Universidade Federal do Rio Grande do Sul (UFRGS) na Linha de Pesquisa: Estudos sobre Infâncias. Graduada em Pedagogia (UFRGS). Professora de Educação Infantil. Integrante do CLIQUE - Grupo de Pesquisas em linguagens, currículo e cotidiano de bebês e crianças pequenas (UFRGS). E-mail: natyscheuer@gmail.com

${ }^{2}$ Pós-Doutor em Educação (UFPEL). Doutor em Educação (UFRGS). Mestre em Educação (UFRGS). Professor do Programa de Pós-Graduação em Educação na Linha de Pesquisa: Estudos sobre Infâncias. Professor da área de Educação Infantil do Departamento de Estudos Especializados (DEE) da Faculdade de Educação da UFRGS. Email: rsaballa@terra.com.br
}

Olhar de professor, Ponta Grossa, v. 24, p. I-24, e-17640.065, 202 I.

Disponível em <https://revistas2.uepg.br/index.php/olhardeprofessor> 
guidelines for the creation of proposals for play facilities, inspired by contemporary art productions. Methodologically, the article consists of three stages. In the first stage, a bibliographic review on the theme is presented. In the second, an inventory of installations produced by contemporary artists is shared. Finally, in the third stage, analyzes of play episodes are presented experienced by children during sections of play facilities. From the analysis, it is possible to infer about the importance of the game facilities as a space for the production of games and performances by children.

Keywords: Child education. Contemporary art. Performance.

Resumen: Desde los Estudios Sociales de la Infancia, en conjunto con los aportes de los estudios de Arte Contemporáneo, el artículo tiene como objetivo discutir la propuesta de las instalaciones de juego en la Educación Infantil, como contextos para la producción de performances por parte de los niños a través de sus interacciones y juegos. En consecuencia, el artículo también presenta pautas para la creación de propuestas para instalaciones de juego, inspiradas en producciones de arte contemporáneo. Metodológicamente, el artículo consta de tres etapas. En la primera etapa se presenta una revisión bibliográfica sobre el tema. En la segunda se comparte un inventario de instalaciones realizadas por artistas contemporáneos. Finalmente, en la tercera etapa, se presentan análisis de episodios de juego, vividos por los niños durante las secciones de las instalaciones de juego. De este análisis se puede inferir, sobre la importancia de las instalaciones de juego como espacio para la producción de juegos y performances por parte de los niños.

Palabras-clave: Educación Infantil. Arte Contemporáneo. Performance.

\section{Considerações Iniciais}

Episódio I - Uma proposta, milhares de possibilidades

Em uma sala vazia com um arranjo de tecidos coloridos de 2 metros de altura, iniciamos a quinta sessão de brincadeira, com a instalação de jogo inspirada em uma obra de Mitsuo Miura ${ }^{3}$. Ao chegarem na sala as crianças demonstraram surpresa. A partir das expressões curiosas das crianças, foram surgindo passos apressados em torno dos tecidos, toques e diferentes ideias sobre a instalação. Helena ${ }^{4}$ entusiasmada exclamou: “Nossa, um arco-íris de entrar, gente!”, rapidamente surgiram outras possibilidades, "a sala virou uma teia de aranha" diz a Júlia, enquanto Joana pondera: "eu acho que parece mais uma cama de dormir". Helena, que ouvia as colegas, retoma a palavra e fala "Nãoo, (fala o apelido da pesquisadora), na verdade é uma chuva de arco-íris. Cuidadoo!” (Notas do diário de campo 5 , maio de 2018).

Mediante a leitura deste episódio é possível perceber que, entre as diversas possibilidades de significação da instalação de jogo (RUIZ DE VELASCO GÁLVEZ; ABAD MOLINA, 20I9), as três meninas demonstram com suas perspectivas criativas, como um mesmo contexto pode receber diferentes qualificações a partir do olhar de cada criança. Dessa maneira, em muitos momentos, as

\footnotetext{
${ }^{3} \mathrm{O}$ artista Mitsuo Miura Mitsuo Miura é natural do Japão, desenvolveu trabalhos com desenhos, gravuras, pinturas, fotografias e instalações. A proposta citada foi inspirada por uma instalação apresentada na exposição "Memorias Imaginadas".
}

${ }^{4}$ Tendo em vista, o compromisso ético de preservação de suas identidades, utilizamos um nome fictício para se referir às crianças. Ademais, o trabalho investigativo foi aceito, mediante a autorização da instituição, assinatura do Termos de Consentimento Livre e Esclarecido - TCLE, pelos responsáveis das crianças e Termo de Assentimento - TALE pelas crianças participantes.

${ }^{5}$ Episódio do diário de campo do TCC realizado na conclusão da Graduação em Pedagogia (20I8/2) com crianças de 2 anos e meio a 5 anos, orientado pelo prof. Dr. Rodrigo Saballa de Carvalho. Convidamos à leitura: SANTOS, Nathalia Scheuermann dos. Arquiteturas efêmeras de jogo na Educação Infantil: Crianças e Arte Contemporânea. Porto Alegre, 2018. 138p. Monografia (Trabalho de Conclusão de Curso) - Licenciatura em Pedagogia, Faculdade de Educação, Universidade Federal do Rio Grande do Sul, Porto Alegre, 2018. Disponível online em: <lume.ufrgs.br/handle//0|83//81995>. 
crianças nos convidam com suas ações a olhar por meio de outras lentes, a ressignificar o comum. Corroborando o argumento, Cunha (2005, p. 98) afirma que "as crianças e a arte contemporânea experimentam, recriam e nos possibilitam recriar outros olhares sobre o mundo".

Diante dessas considerações, compreendemos que os questionamentos compartilhados por Cohen (2002, p. 37): “Qual o desígnio da arte: representar o real? Recriar o real? Ou, criar outras realidades?", suscitam outras indagações para pensarmos no campo da Educação Infantil. Desse modo indagamos: Qual é o desígnio da arte nas Escolas da Infância? Reproduzir, recriar ou criar outras possibilidades? Sem o intuito de apresentar respostas fechadas para tais questões, consideramos que elas podem mobilizar novas perspectivas para pensar as propostas que envolvem a arte no trabalho pedagógico com as crianças na Educação Infantil. Desse ponto de vista, propomos uma ampliação das possibilidades de criação de propostas inspiradas pela arte contemporânea que não se limitem à reprodução ou recriação de obras dos artistas. Ao contrário, defendemos que as propostas de arte no trabalho com as crianças devem ter intencionalidade dos/as docentes e oportunizem espaços para espaços para produção de performances (SCHECHNER, 2013) por meio das brincadeiras que são realizadas pelas crianças.

Em tal direção, Abad Molina (2008) destaca que é possível levar a arte contemporânea para os diversos espaços da escola, a partir da interpretação das obras de acordo com as possibilidades de cada contexto. A partir dessa perspectiva, as instalações de jogo, de acordo com Ruiz de Velasco Gálvez e Abad Molina (2019) são definidas como contextos de jogo, cuja seleção de materiais, organização do espaço e provocações estéticas, estão pautadas em instalações de arte, produzidas por artistas contemporâneos/as. Destarte, tais instalações "diferem-se da criação de um artista, pois se trata de uma proposta que será articulada para determinado contexto escolar pelo professor, considerando os materiais, espaços, tempos e a potencialidades destes" (SANTOS; CARVALHO, 2019, p. 9). Desse modo, defendemos o argumento de que a proposta de trabalho, a partir das instalações de jogo, podem ser caracterizadas como um lugar para vivenciar novas experiências por meio do jogo e da brincadeira em espaços que são abertos para exploração das crianças. Tal proposta, se caracterizam como "espaços que sugerem o era uma vez como convite (e também provocação) para continuar uma e mil histórias onde o adulto propõe, mas é a criança quem interpreta os objetos e espaços oferecidos" 6 (RUIZ DE VELASCO GÁLVEZ; ABAD MOLINA, 20I I, p. 23).

Nessa direção, a arte contemporânea opera como inspiração para criação de instalações de jogo (RUIZ DE VELASCO GÁLVEZ; ABAD MOLINA, 2019) à medida que possibilita o encontro entre crianças, materialidades e espaços. Isso porque, entendemos que a arte possibilita com que as crianças

\footnotetext{
${ }^{6}$ As traduções citadas ao longo do texto são livres (espanhol - português).

Olhar de professor, Ponta Grossa, v. 24, p. I-24, e-17640.065, 202 I.

Disponível em <https://revistas2.uepg.br/index.php/olhardeprofessor>
} 
As crianças e suas performances em contextos de instalações de jogo...

ressignifiquem objetos cotidianos e configurem os espaços a partir de outras perspectivas. Diante do exposto, consideramos importante, compartilhar o modo como compreendemos a arte contemporânea no contexto de nosso trabalho. Assim, concordamos com Cunha (20l7b) quando a autora aponta que são características da arte da contemporaneidade, a tendência à ruptura das fronteiras entre as linguagens (pintura, desenho, escultura, gravura, fotografia...) e da rigidez entre elas. Por conseguinte, também concordamos com Nalini (2015, p. 57), quando afirma que utilização de materiais e objetos de uso comum do cotidiano e da "superação do campo estrito da forma pela busca de novos conteúdos e significados permitidos pela imagem". De fato, acreditamos que a arte contemporânea, pode ser entendida como inauguração do inesperado e como aquela que desperta questionamentos. Ou seja, como um vetor de provocação, espanto e encantamento.

Em suas discussões, Cocchiarale (2006) argumenta que o artista contemporâneo inventa sua própria técnica, sua poética ao longo de seu processo de trabalho. Logo, os/as artistas contemporâneos/as, como afirma Barbieri (2012) não estão preocupados com fronteiras fixas entre as linguagens, assim como as crianças em suas brincadeiras, produções e ações. Não há uma demarcação entre as fronteiras do que se faz, se vive, de modo aproximado na arte contemporânea esses limites são rompidos, mesclam-se uns aos outros. Em tal contexto, por exemplo, quando propomos instalações de jogo (RUIZ DE VELASCO GÁLVEZ; ABAD MOLINA, 2019) às crianças, percebemos que elas cantam, dançam, desenham, interagem. Ou seja, por parte das crianças, tal como afirma Santos (2018), não há uma preocupação em delimitar ou distinguir o que se faz em cada situação. Portanto as linguagens - oral, visual, plástica, corporal - estão imbricadas umas às outras. A esse respeito, Machado (2010a, p. 126) corrobora com o exposto, ao pontuar que as crianças desde muito cedo se expressam por dizeres em ação, contando narrativas por meio de seus corpos, "gestualidade, gritos, choro, expressões de alegria e consternação, espanto e submissão". Tais dizeres em ação, de acordo com Machado (2010a, p. 126) apresentam-se "repletos de teatralidades: pequenas, médias e grandes performances".

A partir dessa exposição inicial, destacamos que nesse artigo temos como objetivo discutir a proposição de instalações de jogo na Educação Infantil como contextos de produção de performances pelas crianças através de suas interações e brincadeiras. Por conseguinte, $\mathrm{O}$ artigo também apresenta indicativos para a criação de propostas de instalações de jogo, inspiradas em produções de arte contemporânea. Portanto, compartilharemos nossas discussões em três etapas. Inicialmente apresentaremos uma revisão bibliográfica sobre a temática das instalações de jogo. Por conseguinte, na segunda etapa, compartilharemos um inventário de instalações produzidas por artistas 
contemporâneos. Na terceira etapa, serão apresentadas análises de episódios de brincadeira ${ }^{7}$, vivenciados por crianças durante seções de instalações de jogo. Por fim, a partir das análises, inferiremos, sobre a importância das instalações de jogo como espaço de produção de brincadeiras e performances pelas crianças.

Posto isso, na próxima seção discutiremos aspectos teóricos acerca das instalações de jogo (RUIZ DE VELASCO GÁLVEZ; ABAD MOLINA, 2019), evidenciando o conceito e as possibilidades que abarcam a proposta de trabalho, assim como sua relevância para a Educação Infantil.

\section{Instalações efêmeras de jogo}

Para discutirmos as contribuições de Abad Molina e Ruiz de Velasco Gálvez (2019) acerca das instalações de jogo é importante compartilhar algumas características da arte contemporânea. A arte contemporânea, conforme assegura Delavald (20/3), pode ser entendida como um convite aberto a todo e qualquer espectador que queira interagir, logo este não só ocupa a posição de contemplação, mas também tem a possibilidade de modificar e ser parte da obra que se apresenta. Posto que, tal como afirma Pontes (2016), em linguagens como a instalação, o corpo, o espaço e o contexto daquele local ganham novos significados e importância a partir da vivência de se estar na arte. Desta forma, Orofino (2017, p. I3I), destaca que o artista ao oportunizar a participação das pessoas, cria um espaço de encontro e convívio, bem como "uma relação de cumplicidade com o público, oferecendo um trabalho em coautoria" com aqueles que visitam as obras. Corroborando o exposto, Díaz-Obregón Cruzado (2003) afirma que os sujeitos que visitam uma instalação desenvolvem um papel ativo na mesma.

A partir da ausência de fronteiras e limitações fechadas, do hibridismo das linguagens e manifestações das diferentes modalidades expressas no tempo presente, podemos dizer que a arte contemporânea nos possibilita desenvolver um olhar aguçado e questionador "sobre o mundo e a potência das experiências culturais, problematizadas, como propulsoras dos modos singulares de expressão" (CUNHA, 20II, p. I 19). Sob esse viés, um trabalho em diálogo com a arte contemporânea na Educação Infantil implica pensarmos a partir da abertura de sentidos e não da delimitação. Ou seja, possibilita pensarmos na promoção do questionamento e da participação de todas as crianças envolvidas.

Em concordância Abad Molina (2008), salientamos que oportunizar às crianças novas propostas e espaços, os quais sejam sugestivos, convidativos e abertos a possibilidades, se caracteriza

\footnotetext{
${ }^{7}$ Trabalho de conclusão de curso de Licenciatura em Pedagogia, intitulado "Arquiteturas efêmeras de jogo na Educação Infantil: Crianças e Arte Contemporânea” (SANTOS, 2018).
} 
As crianças e suas performances em contextos de instalações de jogo...

como um convite à brincadeira, à ação simbólica e aos discursos narrativos. Nesse sentido, as instalações de jogo (RUIZ DE VELASCO GÁLVEZ; ABAD MOLINA, 2019) se constituem como propostas que oportunizam uma configuração específica do espaço, a qual aparece e desaparece (ABAD MOLINA, 2008) ao final de cada sessão. Uma vez que esta inicia e termina dentro de determinado período de tempo modificando o ambiente que as crianças já conhecem e estão habituadas, provocando assim outros sentidos para aquele espaço (SANTOS, 20I8).

Dessarte, por meio das propostas envolvendo instalações de jogo (ABAD MOLINA; RUIZ DE VELASCO GÁLVEZ, 2019), cria-se uma possibilidade de acesso à arte pelas crianças como uma experiência individual e coletiva que constitui seus cotidianos nas Escolas da Infância. De maneira que, assim como as instalações de arte provocam o público a estar imerso nelas, as proposições referenciadas também oportunizem estar dentro delas, por inteiro, com os objetos e com as outras crianças, em uma dinâmica que possibilita o acesso ao simbólico e a construção de significados (ABAD MOLINA, 2008). Dessa maneira, Abad Molina Ruiz de Velasco Gálvez (2019) argumentam que a partir da proposição de instalações de jogo, a escola se torna um dos lugares privilegiados para o conhecimento estético, a percepção e as trocas, interações, organizadas por meio das coreografias criadas no brincar.

Tais propostas, de acordo com Abad Molina (2008), oportunizam o desenvolvimento por parte das crianças de diferentes ações e expressões corporais, as quais envolvem criar e testar possibilidades, e ainda, recriá-las a partir de outras alternativas. Dessa maneira, destacamos que as instalações de jogo (RUIZ DE VELASCO GÁLVEZ; ABAD MOLINA, 2019) oportunizam às crianças uma dinâmica de caos, por meio da qual elas podem desfazer a organização estabelecida pelo adulto inicialmente, como forma de apropriação e interpretação do espaço lúdico pelas crianças (ABAD MOLINA; RUIZ DE VELASCO GÁLVEZ, 2019). Ou seja, a ordem estabelecida inicialmente, se transforma a partir das explorações que são nela realizadas.

A partir desse ponto de vista, as instalações de jogo (ABAD MOLINA; RUIZ DE VELASCO GÁLVEZ, 2019) também possibilitam uma configuração específica do espaço, a qual aparece e desaparece (ABAD MOLINA, 2008) ao final de cada sessão. Uma vez que tal proposta é delimitada por um recorte de tempo (inicia e termina dentro de determinado período na jornada escolar) que em sua extensão modifica $\circ$ ambiente que as crianças conhecem e estão habituadas, provocando outros sentidos e significados para o espaço. Em vista disso, Abad Molina e Ruiz de Velasco Gálvez (201 I; 2019) afirmam que as instalações de jogo possuem as propriedades de um espaço lúdico configurado como um contexto reconhecível, oferecendo à criança uma experiência estética compartilhada para a expressão de seu imaginário simbólico e a possibilidade de transformação.

Olhar de professor, Ponta Grossa, v. 24, p. I-24, e-17640.065, 2021.

Disponível em <https://revistas2.uepg.br/index.php/olhardeprofessor> 
Tendo em vista o exposto, Lapolla, Arce e Mucci (2017) defendem que a introdução das instalações como experiência estética no contexto escolar, possibilita às crianças o desenvolvimento da criatividade, da capacidade lúdica, da imaginação e trabalho colaborativo. Inspiradas por Abad Molina (2008) as autoras propõem tal possibilidade pedagógica de maneira diferente, a partir da criação das instalações coletivamente com as crianças. Na perspectiva, apontada por Lapolla, Arce e Mucci (2017) os adultos atuam como mediadores que auxiliam e orientam as crianças na gestão de seus projetos. Desse ponto de vista, destacamos a potencialidade de se pensar e organizar os processos envolvidos na construção com as crianças, por meio da qual é possível, projetar, conversar, pesquisar por instalações artísticas, modos de trabalho dos artistas e materiais utilizados.

Nesse sentido, para a construção de instalações com as crianças, Lapolla, Arce e Mucci (2017) esclarecem que são criados desenhos para projetar a organização dos objetos e ocupação deles no espaço. Quando possível, as autoras ressaltam que realizam visitas a exposições dos artistas referências ou pesquisa na internet sobre eles. Antes de iniciar a montagem da proposição, Lapolla, Arce e Mucci (2017), oportunizam às crianças momentos de exploração dos materiais que virão a ser utilizados ou que se relacionam com a obra dos artistas que as inspiraram. Por fim, a instalação é montada a partir das projeções realizadas e de acordos coletivos realizados no processo em grupo. Diante disso no processo pedagógico evidenciado, as referidas autoras afirmam que ao entrar em uma instalação, as crianças experimentam possibilidades oferecidas pelos objetos em relação ao espaço, explora-se de maneira física os mesmos e novas descobertas são possíveis por meio do simbólico, das múltiplas explorações e de projetos individuais e coletivos.

A esse respeito, as contribuições de Lapolla, Arce e Mucci (2017) através da descrição dos momentos que foram oportunizados às crianças no desenvolvimento das proposições podem, assim como Abad Molina e Ruiz de Velasco Gálvez (2019), inspirar práticas artísticas na Educação Infantil que se descentrem do tecnicismo (CUNHA, 2005) e promovam espaços para a criação, a ressignificação de objetos e espaços, e para a expressão das performances das crianças. Assim, ambas perspectivas de trabalho oportunizam articular diferentes materiais e linguagens, com base em referenciais da arte para constituir propostas pedagógicas nas quais as crianças possam observar, explorar e criar suas ações expressivas de maneira individual e coletiva.

Diante dessas considerações, na próxima seção apresentaremos um inventário de três artistas contemporâneos/as que trabalham com instalações, buscando elencar como determinados aspectos de suas obras e a poética envolvida nas mesmas, podem inspirar possibilidades de criar instalações de jogo (RUIZ DE VELASCO GÁLVEZ; ABAD MOLINA, 2019). 
As crianças e suas performances em contextos de instalações de jogo...

\section{Inventário de artistas contemporâneos/as que trabalham com instalações}

A arte contemporânea como possibilidade para criar proposições pedagógicas nas Escolas da Infância, "pode contribuir para a ampliação de repertórios e para a rede que envolve a imaginação, a criação, a percepção e a emoção das crianças" (CUNHA, 2005, p. 96). No entanto, é necessário considerar a intencionalidade dos materiais, a combinação entre eles e a composição de tais elementos na configuração do espaço. Para auxiliar nesse processo consideramos importante o/a docente indagar antes de planejar: Quais são as possibilidades de usos e ações que os materiais que serão selecionados oferecem? Quais outros materiais podem ser incluídos para potencializar as ações das crianças? A partir do espaço físico disponível para a proposição da instalação de jogo, de que modo as obras que serviram de inspiração, podem ser ressignificadas no contexto pedagógico?

A esse respeito, Abad Molina (2008), evidencia que devem ser considerados os aspectos estéticos, materiais, espaciais, contextuais e perceptivos, para a proposição de instalações de jogo. A partir dos aspectos elencados pelo referido autor, é preciso reforçar a relevância da sensorialidade dos materiais. Ou seja, em relação aos materiais, é importante destacarmos suas formas, cores, texturas e as possibilidades de composição e transformação destes. Conforme Abad Molina (2008), as ações desenvolvidas pelas crianças nas propostas estão relacionadas aos modos através dos quais elas são planejadas e apresentadas para o grupo pelos/as docentes.

Desse modo, para inspirar possibilidades de planejamento de possibilidades de planejar instalações de jogo (ABAD MOLINA; RUIZ DE VELASCO GÁLVEZ, 2019) com as crianças, compartilharemos um inventário de artistas contemporâneos/as que produzem instalações e, que desse modo, tem nos possibilitado pensar em propostas para ser desenvolvidas com as crianças que temos trabalhado. De fato, não apenas as obras dos artistas - o produto, organização final - pode inspirar o planejamento das instalações de jogo. Ora, os modos com os quais os/as artistas desenvolvem suas obras, ou seja, os processos implicados na produção de suas poéticas, também podem ser considerados como referência. Portanto, é possível pesquisar por artistas para inspirar as propostas com base em suas obras, a partir dos materiais utilizados por eles/elas ou ainda por meio dos processos que desenvolvem durante a criação de suas obras.

Para a realização da pesquisa e seleção de artistas e suas respectivas obras, é possível que o/a docente crie ou adapte critérios a partir de seu contexto. Todavia, acreditamos que os critérios compartilhados por Abad Molina (2008) em relação aos modos de escolha de artistas e obras em suas proposições de instalações de jogo também podem contribuir com a qualificação do trabalho docente. Em tal direção, Abad Molina (2008), considera os seguintes critérios: 
I. As possibilidades de interação com os materiais e de gerar narrativas;

2. As possibilidades de uso e de movimentos corporais no espaço;

3. A utilização de diferentes planos na instalação - alto, médio, baixo;

4. As características da obra (cores, formatos, texturas, tamanhos, materiais/objetos);

5. As possibilidades de ressignificação que a obra oferece;

6. Relações da obra com as crianças do grupo (questões culturais, experiências e preocupações).

Ademais, considerar os interesses das crianças em determinado material ou tipo de exploração também pode ser uma oportunidade para criar uma proposta sensível que amplie as possibilidades de interação das crianças com os materiais. Em tal perspectiva, entendemos que planejar propostas de instalações de jogo (RUIZ DE VELASCO GÁLVEZ; ABAD MOLINA, 2019), inspiradas na arte contemporânea, pode oportunizar novas possibilidades de ações, interações e brincadeiras por parte das crianças.

Desse modo, devido aos limites do artigo, optamos nesse momento por apresentar três artistas contemporâneos/as que trabalham de formas diferentes com tecidos - Ernesto Neto, Ulla von Brandenburg e Hélio Oiticica. Destacamos que o critério para seleção dos/as artistas foi o material utilizado em determinadas obras ${ }^{8}$ - tecidos. A escolha por este material acontece por ser algo de fácil acesso, que geralmente está disponível nas escolas e faz parte do cotidiano de muitas crianças. É comum situações de brincadeira com tecidos para cobrir-se, esconder-se, montar cabanas... Mas que outras possibilidades intencionalmente planejadas a arte podem inspirar? Desse modo, prosseguindo a discussão, convidamos você leitor/a a conhecer os artistas:

\section{Ernesto Neto9}

Ernesto Saboia de Albuquerque Neto, nasceu em 1964 no Rio de Janeiro (Brasil) onde vive e trabalha, o artista é um dos nomes mais proeminentes da cena contemporânea. Estudou escultura na Escola de Artes Visuais do Parque Lage (EAV/Parque Lage) e suas produções artísticas situam-se entre a escultura e a instalação. É predominante em seu trabalho, o uso de meias de poliamida, crochê e materiais flexíveis e cotidianos. De modo geral, suas obras convidam a interagir, tocar, entrar...

\footnotetext{
${ }^{8}$ Ressaltamos que os artistas referenciados trabalham também com outros materiais, selecionamos obras específicas para apresentar no artigo, a partir dos tecidos como critério de seleção da pesquisa para este inventário.

9 Para saber mais sobre Ernesto Neto é possível acessar a Enciclopédia do Itaú Cultural: <enciclopedia.itaucultural.org.br/pessoal I848/ernesto-neto>.
}

Olhar de professor, Ponta Grossa, v. 24, p. I-24, e-17640.065, 2021.

Disponível em <https://revistas2.uepg.br/index.php/olhardeprofessor> 
provocam o público a estar de uma outra maneira, diferenciada do comum, convidados a imergir nas instalações de tecidos pendulares e fendas.

Destacamos uma exposição recente de 2019 na Pinacoteca de São Paulo (São Paulo - Brasil) denominada "Sopro". Foi promovida como uma exposição retrospectiva de obras do artista. A mesma reuniu 60 obras de Ernesto Neto de março a julho do ano em questão. As obras exploravam os diferentes planos (baixo, médio e alto), brincavam com o equilíbrio por meio da leveza apresentada pelos tecidos translúcidos e pelo peso de tecidos pendentes que se estendiam quase ou até o chão. Tais formações em tecidos translúcidos, presentes em variadas obras e configurações do artista, nas palavras de Freitas (2016, p. I4) ativam o ambiente por intermédio do tensionamento do tecido "nestas formas pronunciam-se uma qualidade de maciez e consequente acomodação, que as aproximam ainda mais da pele, das dobras e dos volumes do corpo".

Assim, os tecidos como material são trabalhados pelo artista de modo diferente de como tal material é visto habitualmente, como quem questiona maneiras criativas de habitar o espaço consigo e com os outros. As obras da exposição convidam e instigam a outras dimensões de uso do espaço, de imaginar possibilidades de criação com aqueles materiais, das variadas maneiras com as quais é possível se mover e deslocar-se ali. Uma vez que os visitantes são instigados a habitar corporalmente, fazer parte da obra, entranhado aos tecidos a partir de "uma compreensão que avança através da negociação do corpo com espaços de passagem, aberturas, transparências [...]” (FREITAS, 2016, p. I4).

Ernesto Neto, através de suas instalações, coloca em diálogo o tipo de interação de cada um com aquelas obras por meio de "qualidades que falam ao corpo a partir da ativação de uma série de memórias ou reconhecimentos que passam por volumes e por texturas que permitem, de fato, um despertar ao corpo" (FREITAS, 2016, p. 14). Nesse sentido, suas instalações provocam o pensar e a ação corporal através das relações estabelecidas por cada sujeito. Tais aspectos, podem ser profícuos no desenvolvimento de instalações de jogo com as crianças.

\section{Ulla von Brandenburg ${ }^{10}$}

A artista Ulla von Brandenburg é natural de Karlsruhe (Alemanha), nasceu em 1974 e reside desde 2005 em Paris. Estudou cenografia na Universidade de Artes e Design Karlsruhe e artes visuais na Universidade de Belas Artes de Hamburgo. Seu trabalho é marcado por diversas linguagens, desde instalações, filmes, aquarelas, murais, colagens e performances. Obras de Ulla von Brandenburg estão

10 Para saber mais sobre a artista Ulla von Brandenburg e seu trabalho é possível acessar: <pilarcorrias.com/artists/ulla-von-brandenburg> e <palaisdetokyo.com/en/ulla-von-brandenburg>.

Olhar de professor, Ponta Grossa, v. 24, p. I-24, e-17640.065, 2021.

Disponível em <https://revistas2.uepg.br/index.php/olhardeprofessor> 
incluídas em coleções como a do Tate Modern (Londres), MAMCO (Genebra), Centre Pompidou (Paris) e MUDAM (Luxemburgo).

Entre suas obras, destacamos as instalações da exposição denominada "Le milieu est bleu" no Palais de Tokyo (Paris - França) em 2020. Os tecidos de grandes dimensões estendidos atravessam os salões brancos do espaço, os encobrem, camuflam, escondem e vestem como destaca Tilburg (2020). Dessa maneira, os arranjos configurados pela artista criam espaços de travessia por meio das fendas e provocam o público a observar e buscar descobrir o que há por trás de cada tecido, em um movimento que possibilita ao público "sair de um espaço genérico para entrar em espaços mais específicos!"” (TILBURG, 2020, p. 6I). Espaços os quais são democráticos e flexíveis (TILBURG, 2020), e que permitem que cada um possa interpretá-los à sua maneira, atribuindo suas próprias significações e modos de estar, habitar e expressar-se corporalmente.

A multiplicidade dos tecidos em suas cores, texturas, tamanhos, caimentos, cordas, fendas, suspensões, convida o público a adentrar as instalações, a cruzar limites físicos através do movimento de seus corpos. Da mesma maneira, as obras de Ulla von Brandenburg instigam a imaginar outras possibilidades por meio daquele espaço que é construído como barreira, passagem, ou ainda, como possibilidade de criar outros espaços dentro do cubo branco, como retrata Tilburg (2020) - metáfora utilizada pelo autor ao se referir aos espaços expositivos. Consideramos essas perspectivas como potentes possibilidades de diálogo com os interesses das crianças pelos espaços, tecidos e uso desses materiais em suas explorações.

\section{Hélio Oiticica ${ }^{12}$}

Hélio Oiticica, artista performático, pintor e escultor, natural do Rio de Janeiro (1937 - 1980), iniciou em 1954 estudos de pintura e desenho no Museu de Arte Moderna do Rio de Janeiro (MAM/RJ). Durante sua trajetória escreveu textos com reflexões sobre as artes plásticas. No período de 1955 a 1956, o artista participou do Grupo Frente e no ano de 1959, passou a integrar o Grupo Neoconcreto, ao lado de artistas como Reynaldo Jardim, Amilcar de Castro, Lygia Clark, Lygia Pape e Franz Weissmann. A partir desse momento, Hélio passa a criar relevos espaciais, bólides, capas, estandartes, tendas e penetráveis.

\footnotetext{
" Em tradução livre (francês - português) realizada pelos autores.

12 Para saber mais sobre Hélio Oiticica e o seu trabalho é possível acessar os seguintes sites: <mam.rio/artistas/helio-oiticica> e <enciclopedia.itaucultural.org.br/pessoa48/helio-oiticica>.
}

Olhar de professor, Ponta Grossa, v. 24, p. I-24, e-17640.065, 2021.

Disponível em <https://revistas2.uepg.br/index.php/olhardeprofessor> 
As crianças e suas performances em contextos de instalações de jogo...

Destacamos a exposição "Museu é o Mundo" que cobriu todos os períodos de produção artística de Hélio Oiticica. Tendo em vista os tecidos como materialidade escolhida, ressaltamos os Penetráveis, série que com suas cores, formas labirínticas, convidam a entrar, penetrar como instiga o nome. Seja pelos longos tecidos que formam espaços de esconderijo e passagem por suas aberturas ou pelo movimento e soltura do "Penetrável Gal" com suas faixas de tecido azul, Hélio Oiticica provoca o público a perscrutar e construir seus caminhos e vivências pelas obras. Visto que o artista primava por uma participação criativa na qual a arte mobiliza a criatividade e a ação das pessoas (DONADEL, 2010). Os Penetráveis provocam a transformação do espaço em um ambiente vivencial (MARQUEZ, 2009), por meio do qual se estabelece uma dinâmica relacional entre corpo, obra e os demais.

O Penetrável denominado "Rhodislandia" também é uma interessante inspiração para proposições na Educação Infantil, à medida que circunscreve o espaço com tecidos transparentes, criando uma dimensão de espaço que ora pode ser pensado como aberto, ora fechado, posto que o tecido transparente pode ser barreira por sua concretude, mas também possibilidade de miradas. Ainda, a obra instiga a uma participação marcada pela sensorialidade através das folhas, galhos, luz, e inclusive, som devido ao piano apresentado.

Diante dessas características das obras e exposições apresentadas de Ernesto Neto, Ulla von Brandenburg e Hélio Oiticica, na próxima seção compartilhamos possibilidades para criação de instalações de jogo (RUIZ DE VELASCO GÁLVEZ; ABAD MOLINA, 2019) e apresentamos duas imagens de propostas que foram realizadas na pesquisa ${ }^{13}$ (citada anteriormente).

\section{Possibilidades de instalações efêmeras de jogo: compartilhando práticas}

Consideramos importante reiterar a relevância de questionar de que maneira pensamos as instalações de jogo (RUIZ DE VELASCO GÁLVEZ; ABAD MOLINA, 2019), tendo em vista quais são os artistas e obras referentes, a intencionalidade e de que maneira estes se relacionam com os interesses do grupo de crianças para que tenham sentido no contexto. Buscando assim que sejam proposições interessantes, convidativas e esteticamente atrativas.

Procurando articular ideias de instalações de jogo (RUIZ DE VELASCO GÁLVEZ; ABAD MOLINA, 2019) com base nos artistas referenciados na seção anterior, considerando tanto o material utilizado, quanto seus modos de organização e uso dos espaços, consideramos relevante apresentar algumas reflexões. Uma vez que, diante das características que envolvem a arte, como professores e pesquisadores, "somos interpelados por uma profusão de possibilidades inventivas" (VALLE, 2019, p. 83).

\footnotetext{
13 “Arquiteturas efêmeras de jogo na Educação Infantil: Crianças e Arte Contemporânea” (SANTOS, 2018).
} 
Na perspectiva da seleção de artistas e obras a partir do material, Ostetto e Melo (2019, p. 498) corroboram o argumento ao afirmar que

experimentar materialidades, pesquisar características físicas e simbólicas dos materiais enquanto os manipula, pode fertilizar processos de criação que, suscitados por hipóteses formuladas na ação com/sobre a matéria, ampliam possibilidades expressivas, alargando, por sua vez, o conhecimento do mundo (OSTETTO; MELO, 2019, p. 498).

Desse modo, os tecidos enquanto materialidade possibilitam criar novos espaços dentro dos contextos já conhecidos da escola. Assim, os limites físicos impostos pela matéria podem permitir às crianças tanto estar visível quanto não estar, por meio da cobertura do corpo com os tecidos e de suas interações na proposta. Nessa direção, é possível estarem dentro ou fora, e em diferentes lugares na dimensão do real e do imaginado. Ou seja, à medida que as crianças explorarem instalações com tecidos irão criar hipóteses e outros repertórios de usos e ações com este material. Concordando com Ostetto e Melo (2019, p. 505) entendemos que "o contato íntimo com diversas materialidades e suas propriedades, entre aromas, texturas, formas, cores, sons, engendra processos de apropriação e desenvolvimento de diferentes linguagens expressivas".

Compreendemos que é possível articular possibilidades a partir das obras apresentadas e não ideias fechadas para criação de propostas de instalações de jogo (RUIZ DE VELASCO GÁLVEZ; ABAD MOLINA, 2019). Por exemplo, a partir do trabalho de Ernesto Neto salientamos a perspectiva de criar instalações de jogo com tecidos suspensos, explorando diferentes tamanhos de tecidos que podem também possuir diferentes formas. Um exemplo de possibilidade de configuração, é a figura do túnel para constituir espaços de travessia e ocultação ou ainda, "bolsas" que podem conter materiais (como areia) dentro delas para dimensionar pesos variados. Outra possibilidade consiste em utilizar especiarias e chás dentro ou entre os tecidos para aguçar a dimensão olfativa na exploração da proposta. Brincar com as possibilidades de criação de instalações de jogo (RUIZ DE VELASCO GÁLVEZ; ABAD MOLINA, 2019) que proporcionem uma imersão por inteiro nelas. Nessa perspectiva de considerar a suspensão de tecidos e diferentes modos de configuração a partir das obras dos artistas, apresentamos uma instalação de jogo inspiradas em obras da artista Kimsooja ${ }^{14}$ que formava diferentes corredores entre os tecidos.

\footnotetext{
${ }^{14}$ Para conhecer a artista Kimsooja e suas obras é possível acessar seu site <kimsooja.com>.
} 
Figura I: Caminhos possíveis

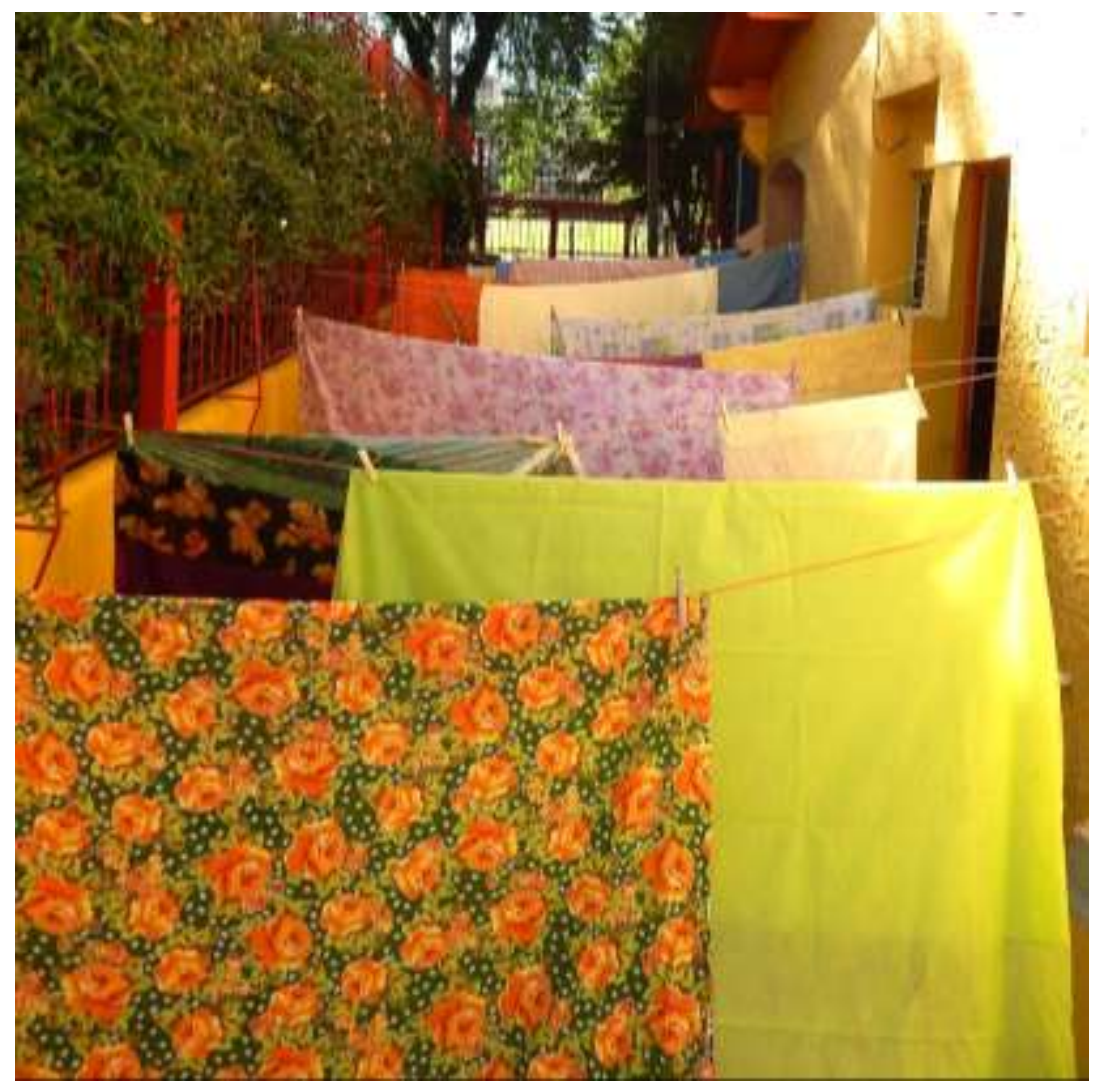

Fonte: Arquivo pessoal, 2018.

Após observar a fotografia, é possível também relacionarmos esta instalação de jogo (RUIZ DE VELASCO GÁLVEZ; ABAD MOLINA, 2019) com características de obras da exposição “Le milieu est bleu" de Ulla von Brandenburg. Uma vez que a artista explora a cobertura dos espaços com tecidos. Tendo em vista essa perspectiva, pode-se oportunizar a criação de novos espaços, cenários, que podem adquirir formatações diversas como por corredores alinhados paralelamente, espaços labirínticos, os quais propiciam ir e vir, testar possibilidades de percursos e inventar novos signos por meio do brincar entre os diferentes tecidos. Outra perspectiva interessante seria o uso de diferentes planos, os tecidos podem estar presos ao teto? Encostando no chão? Em altura média, possibilitando às crianças olhar por cima deles? Ulla von Brandenburg inspira a constituição de fendas, aberturas nos tecidos, que a depender de sua altura, podem suscitar passagens, atravessamentos e olhares. Na produção da artista, "os têxteis desempenham um papel essencial como material dobrável, reutilizável e nômade: o artista recicla tecidos de uma exposição para outra" (TILBURG, 2020, p. 6I) atitude a qual pode ser profícua para as professoras da Educação Infantil. Desse modo, reaproveitar os tecidos em diferentes propostas 
pode oportunizar o reconhecimento deles pelas crianças, assim como a memória do que foi realizado com eles, possibilitando a ampliação de seus repertórios de uso daquele material.

Por sua vez, apresentamos outra instalação de jogo (RUIZ DE VELASCO GÁLVEZ; ABAD MOLINA, 2019) que foi realizada também no âmbito da pesquisa citada anteriormente, para esta proposta $^{15}$ foram amarradas tiras de tecido em uma base de rede ${ }^{16}$ quadrada. Consideramos relevante pontuar que os diversos tecidos que compõem a proposta, foram reutilizados pois seriam descartes de costura.

Figura 2: Entre laços, cordas e tecidos

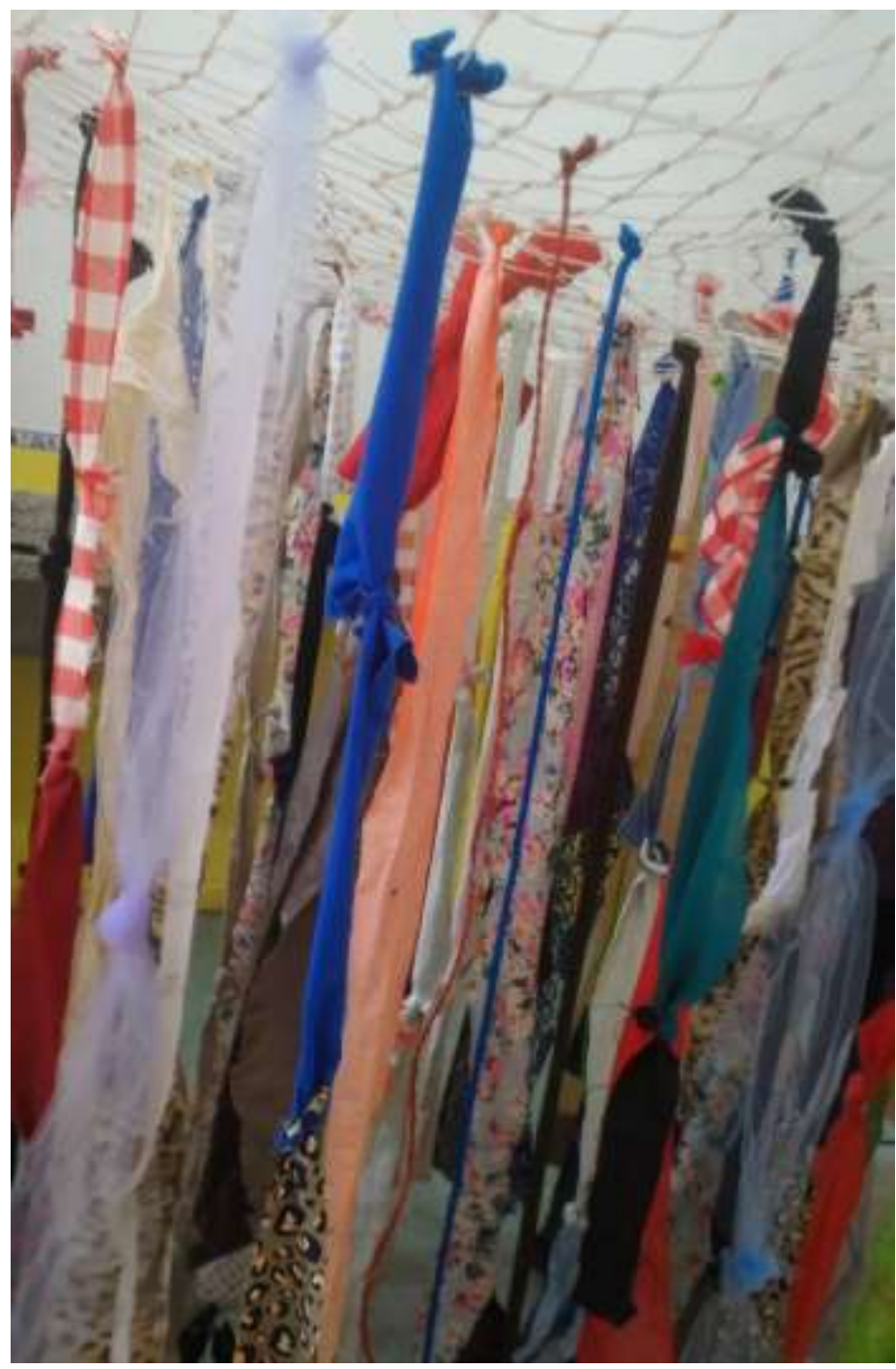

Fonte: Arquivo pessoal, 2018.

\footnotetext{
${ }^{15}$ A referida instalação de jogo foi inspirada em uma obra da artista Bianca Santini, é possível conhecer mais sobre seu trabalho em: <aeergs.com.br/2019/04/16/bianca-santini> e <margs.rs.gov.br/midia/risco-e-ar\%CC\%B6-uma-exposicao-de-bianca-santini>

${ }^{16}$ Rede de tela de proteção utilizada, muitas vezes, em janelas.
}

Olhar de professor, Ponta Grossa, v. 24, p. I-24, e-17640.065, 2021.

Disponível em <https://revistas2.uepg.br/index.php/olhardeprofessor> 
As crianças e suas performances em contextos de instalações de jogo...

Podemos relacionar também essa fotografia da instalação de jogo (RUIZ DE VELASCO GÁLVEZ; ABAD MOLINA, 2019) com a série de obras denominadas Penetráveis de Hélio Oiticica. Uma vez que tais obras oportunizam pensar a criação de instalações de jogo com estruturas ou arranjos de tecidos que pendem até o chão soltos. Ademais, os Penetráveis como inspiração podem favorecer planejar propostas que envolvam cruzar, caminhar, se cobrir e correr por entre cada faixa de tecido. Por outro lado, as obras de Hélio Oiticica também possibilitam pensarmos na construção de caminhos, corredores e "barracas" de tecidos com saídas que ligam umas às outras. Em tal perspectiva, é interessante o uso de espaços abertos com incidência de luz solar para produzir sombras a partir da organização proposta ou a combinação com projeção em uma sala escurecida.

As questões pontuadas a partir de cada um dos três artistas possibilitam criar diferentes instalações de jogo trabalhando, essencialmente, com um mesmo material, os tecidos. No entanto, cabe ressaltar que tais propostas podem ter mais de uma obra como referência, combinando ideias e usos dos materiais. Assim como é possível também dar continuidade às propostas a partir das explorações das crianças e por meio da busca de outros artistas e obras.

Com base nas obras de Ernesto Neto, Ulla von Brandenburg e Hélio Oiticica elencadas anteriormente, além dos tecidos como material comum, destacamos algumas características dos processos dos artistas apresentados que podem ser interessantes para constituir proposições:

- Uso do plano alto;

- Suspensão dos tecidos;

- Grande quantidade de materiais utilizados;

- Transformação dos espaços;

- Ressignificação do material;

- Implicação do corpo do público nas obras.

Nessa perspectiva, entendemos a instalação de jogo como uma arquitetura do acontecimento nos contextos escolares, como vivência pedagógica (ABAD MOLINA; RUIZ DE VELASCO GÁLVEZ, 2019). Conforme discutimos neste até o momento, tem um caráter intencional, pedagógico e diferese de uma reprodução literal das instalações de arte.

Portanto, salientamos que as possibilidades de trabalho compartilhadas, se caracterizam tão somente como ideias e reflexões para inspirar práticas. Na próxima seção, iremos apresentar as análises do artigo a partir do compartilhamento de episódios de brincadeiras vivenciados por crianças no contexto de pesquisa com seções de instalações de jogo.

Olhar de professor, Ponta Grossa, v. 24, p. I-24, e-17640.065, 202 I.

Disponível em <https://revistas2.uepg.br/index.php/olhardeprofessor> 


\title{
Instalações efêmeras de jogo, crianças e performances
}

\begin{abstract}
Episódio 2 - Em busca de uma cama
No decorrer da exploração da instalação de jogo formada por largos corredores de tecidos, as crianças brincavam em projetos coletivos e individuais. Ao passo que Frederico começa a caminhar mais devagar e a passar de tecido em tecido, tocando neles. Vai até a pesquisadora e diz: "estou procurando minha cama, a melhor cama". Em seguida, ele atravessa toda a instalação de jogo, testando possibilidades, se enrola, cheira, encosta no rosto e segue sua busca observando em silêncio. Até que se enrola abraçado em dois tecidos, olha para a pesquisadora sorrindo e diz: "eu achei a minha cama!!! Ela é fofinha" e como quem se "deita" fecha os olhos e de pé vira para um lado e para o outro (Notas do diário de campo, maio de 20/8).
\end{abstract}

Mediante a leitura do episódio compartilhado, é possível perceber que Frederico se apropria dos tecidos, atribuindo um novo sentido a um material que já the é conhecido. Ele cria um contexto por meio do qual suas ações corporais são expressas em relação ao material, então se enrola, toca, cheira, se esconde e aparece. Assim, em consonância a Abad Molina e Ruiz de Velasco Gálvez (2019, documento eletrônico ${ }^{17}$ ) a "coreografia espontânea lúdica gera uma surpreendente variedade interpretativa dos espaços, objetos e relações [...]" criadas pelas crianças através de suas ações lúdicas para ressignificar o proposto, criando novos ordenamentos na instalação.

Desse modo, brincar, explorar, interagir em propostas de instalações de jogo, inaugura novas formas de relação, de ser e estar com o outro, consigo e com aqueles objetos em determinado contexto. As crianças apropriam-se da instalação ao criar projetos e modificar a ordem apresentada por meio da gestão e transformação do espaço e objetos. A esse respeito, Abad Molina e Ruiz de Velasco Gálvez (2019) corroboram o argumento ao afirmar que meninos e meninas em interação entre si e com os objetos, estabelecem um diálogo criativo. Em tal direção, compartilhamos a seguir um episódio de uma pesquisa com crianças, na qual, foram desenvolvidas sessões com instalações de jogo. A situação focaliza como as crianças ressignificam objetos e atribuem sentidos criativos aos mesmos, assim como produzem performances de fazer de conta (SCHECHNER, 20I3) as quais estão atreladas ao brincar:

\begin{abstract}
Episódio 3 - Entre as teias de aranha
Nesta tarde da pesquisa de campo, em meio a sessão com instalação de jogo, surgem giros e enrolações no arranjo de tecidos suspenso desde o teto. Rapidamente Maria Luisa para todos os colegas ao gritar, olhando para a colega Lara, "uma aranha, socorroo!!!”. Lara que nesse momento brincava com outro colega, vira-se para ela e movimenta-se como os braços esticados - fingindo ser "aranha". E complementa, "Eu vou te pegar" e corre até Maria Luisa puxando diversos pedaços de tecidos. Maria Luisa clama por socorro entre os colegas que resolveram gritar juntos em coro
\end{abstract}

\footnotetext{
${ }^{17}$ E-book Kindle intitulado “El lugar del símbolo: El imaginario infantil en las instalaciones de juego”, citação da primeira seção do segundo capítulo do livro, posição 1043 (aproximada).
} 
As crianças e suas performances em contextos de instalações de jogo...

"socorroo". Ao chegar na colega, a Lara que estava pronta para enrolá-la com pedaços de tecidos é surpreendida. Maria Luisa prontamente puxa as faixas de tecidos para volta sua volta e comemora "estou presa! Mas agora eu que sou a aranha gigante!!!" (Notas do diário de campo, maio de 2018).

É possível observar através da leitura que as crianças investem novos sentidos e conotações aos objetos a partir de seus projetos, os tecidos nesse episódio oferecem concretude a uma teia de aranha, assim como foram ao longo da sessão, quarto, cama, festa de carnaval e esconderijo. Tal fato evidencia a necessidade de observar as explorações infantis de maneira viva e relacional, assim como seus usos imaginativos dos objetos (MACHADO, 20I0a). Da mesma maneira, essas possibilidades criadas pelas crianças demonstram também a característica polimorfa delas, relacionada a sua capacidade para transformação e como "é parte do próprio código da brincadeira ser mutante" (MACHADO, 20I0b, p. 87).

No episódio narrado, Maria Luisa assume o papel de alguém com receio de aranha e para isso, atribui outro papel à colega. A menina convoca os colegas por meio da expressão oral, modificando a entonação de sua voz ao gritar ao mesmo tempo que expressa corporalmente. Realiza uma performance de fazer de conta, na qual para Schechner (2013) existe a distinção entre o que é real e o que é encenado, fronteira que é mantida de modo nítido. Tal questão, também é discutida por Fians (2015) ao destacar que fingir ser determinado papel, significa estabelecer relações com ele e não o assumir por inteiro. Uma vez que da mesma maneira que a criança finge ser o personagem, também finge não ser ela mesma. Fingir ser de mentirinha, possibilita reapropriações, interpretações que tangem às particularidades de si e do momento e não uma imitação fidedigna, mas sim uma forma de "fazer do meu jeito" (FIANS, 20I5).

Desse ponto de vista, as performances de faz de conta mantêm uma limitação marcada entre o mundo da performance e a realidade cotidiana, as crianças em suas brincadeiras exemplificam isso, sabem que estão encenando e inclusive podem narrar isto oralmente (SCHECHNER, 20I3). Ressaltamos em concordância com Fians (20I5) que existe uma leveza e fluidez pelas quais as crianças transitam entre ser de verdade e de mentirinha. E justamente essa possibilidade de deslocamento entre verdade/mentirinha, realidade cotidiana/performance, que oportuniza $\circ$ brincar com seus próprios significados (FIANS, 20I5). Desse modo, Caon (2017, p. I24), argumenta que se trata de "um teatro que transborda da vida cotidiana, comentando-a, parodiando-a, apropriando-se dela", assim as crianças performam, nesse caso, sem uma determinação do que/como fazer.

Na mesma direção, Abad Molina e Ruiz de Velasco Gálvez (20II, p. I56) indicam que na concepção espacial das instalações de jogo, as crianças "as vive[m] e as interpreta[m] como um ator que se move no palco criado para o desenvolvimento de uma determinada ação". Assim, cada proposta de instalação estabelece um novo cenário escolar nas instituições, criando em certa maneira, uma

Olhar de professor, Ponta Grossa, v. 24, p. I-24, e-17640.065, 202 I.

Disponível em <https://revistas2.uepg.br/index.php/olhardeprofessor> 
perturbação, nas rotinas e nos modos de relacionamento de crianças e adultos (RUIZ DE VELASCO GÁLVEZ; ABAD MOLINA, 2019).

De fato, as explorações com instalações de jogo (RUIZ DE VELASCO GÁLVEZ; ABAD MOLINA, 2019), oportuniza diferentes possibilidades de interações, imaginários, expressões e ações, nas quais as relações entre as crianças, com o espaço e os objetos são significadas de uma nova maneira. Ademais, por meio das ações individuais e coletivas das crianças a proposta se transforma e modifica, no encontro com está e com os que ali estão. Em tal perspectiva, de acordo com Ruiz de Velasco Gálvez e Abad Molina (20II, p. 156) são favorecidas "múltiplas situações de aprendizagem e descobertas geradas de forma espontânea" através das ações das crianças.

\begin{abstract}
Episódio 4 - $O$ baile na floresta
A última proposição da pesquisa envolveu uma instalação de jogo composta por diversos retalhos e pedaços de tecidos em um largo arranjo suspenso no teto da sala. As crianças organizaram em um primeiro momento os papéis e o contexto da brincadeira: "Eu sou a mãe, a Maria Luisa é a filha e ela tem um baile para ir", retomava Lara. Então as meninas começam a dançar em torno da instalação, entre rodopios e passos para os lados, elas cantam canções. Eis que Maria Luisa começa a correr por entre os tecidos e apressada fala: "corree, mãe, rápido, tem um caçador". As duas estabelecem uma dinâmica de entrar e sair da proposta, ora uma está dentro, enquanto a outra está fora. Após certo tempo, Lara expressa: "Eu vi o lobo lá dentro na floresta". As duas meninas começam a conversar quase que cochichando olhando para os tecidos até que aparece João dizendo: "Cadê esse lobo". E em seguida, Valentina explica "é que o caçador, tá procurando o lobo e não acha". Maria Luísa responde de imediato: "Mas o lobo é muito perigoso, cuidado! Tô com medo de ir na floresta!" e seguem correndo gritando "aaa" por dentro da instalação (Notas do diário de campo, maio de 2018).
\end{abstract}

As performances de fazer de conta (SCHECHNER, 2013) narradas no episódio evidenciam o que Machado (2010a) argumenta a respeito dos modos imaginativos das crianças de leitura do mundo, os quais encontram-se relacionados ao polimorfismo. A vida das crianças é repleta de momentos que as envolvem "de tal maneira que seu corpo adere às situações: a experiência é vivida com vigor e intensidade" (MACHADO, 20I0a, p. 12I). A partir do dito por Machado (2010a), é possível destacarmos que no episódio compartilhado as crianças envolveram-se com os materiais, os espaços e entre si ressignificando o que foi proposto, criando diferentes brincadeiras no âmbito coletivo e individual. Isso porque, tal como assegura Machado (2010a, p. 125), a infância é um "período marcado pela oralidade, pelo corpo vivido, pela experiência intensa de busca das novidades do mundo". Por essa razão, Machado (2010a) propõe "enxergar na criança a autoria de sua própria socialização, vendo-a realizar um work in process - trabalho em processo - acerca de um tempo feito não de linearidade factual, mas sim de experiências do agora" (MACHADO, 20I0a, p. I25).

Corroborando o exposto, Singer (2019) argumenta que o intuito é pensar a escola como um espaço de múltiplas possibilidades no qual meninos e meninas possam se apropriar de diversas 
As crianças e suas performances em contextos de instalações de jogo...

linguagens e materialidades. Portanto, podemos considerar as instalações de jogo (RUIZ DE VELASCO GÁLVEZ; ABAD MOLINA, 2019) como uma das maneiras de possibilitar e aprofundar diferentes caminhos para as experiências das crianças nas escolas de Educação Infantil, como um convite a explorar, perguntar, construir, transformar e imaginar.

Nesse sentido, concordamos com Caon (2017) ao indicar que consiste em dar relevância às experiências corporais, gestuais, orais, ou seja, as performances, realizadas pelas crianças nos espaços e tempos que são compartilhados dentro da escola. De acordo com Icle (2013) o corpo nas escolas para ser potencializado e não docilizado. Sob esse viés, da potência e da possibilidade, Machado (2010a) destaca que cada ato, ação, poderá ser lido como performativo, para tanto, o adulto como observador, tem o papel de inventariar os modos de ser das crianças.

Assim, a partir do entendimento das instalações de jogo como um espaço potente e sensível para exploração e expressão das crianças por meio de suas performances e narrativas, apresentamos na próxima seção as considerações finais do artigo.

\section{Considerações Finais}

A partir das discussões compartilhadas no decorrer do artigo, consideramos importante destacar que a arte contemporânea, em sua variedade de materialidades, suportes, espaços, sentidos e estética, possibilita inspirações interessantes e potenciais referentes a criação de instalações de jogo (RUIZ DE VELASCO GÁLVEZ; ABAD MOLINA, 2019). Como inspiração, a arte contemporânea pode propiciar situações que envolvam objetos do cotidiano e espaços em contextos diferentes do habitual, possibilitando que as crianças se expressem através de diferentes linguagens. Tais propostas podem contribuir ainda com o senso estético das crianças, ampliando-o para além de formas fechadas. Nesse processo, as crianças podem ser instigadas a solucionar problemas, a imaginar outras possibilidades de uso dos materiais, a questionar, exercitando a autoria e novas formas de expressão (IAVELBERG, 20I7; CUNHA, 2017b) a partir do encontro com o novo ou mesmo com o conhecido, no entanto, ressignificado.

Em tal perspectiva, as instalações de jogo se caracterizam como propostas que têm como inspiração instalações de arte, são planejadas para um contexto educativo e possibilitam a transformação da organização apresentada por parte das crianças (ABAD MOLINA, 2008). O que acontece por meio das interações e explorações corporais das crianças que criam possibilidades de ampliação de seus repertórios de ações, gestos e movimentos. A esse respeito, Machado (2010a, p. II7) corrobora ao defender que as ações das crianças ganham espaço e vitalidade em "contextos sensíveis, inteligentes, vivos: algo muito próximo daquilo que, em arte contemporânea, nomeiam-se

Olhar de professor, Ponta Grossa, v. 24, p. I-24, e-17640.065, 202 I.

Disponível em <https://revistas2.uepg.br/index.php/olhardeprofessor> 
instalações". Logo, as instalações de jogo podem ser contextos privilegiados para acessar a arte e criar novos cenários no cotidiano escolar (ABAD MOLINA, 2008).

Portanto, reiteramos que o intuito não é reproduzir ou recriar obras de arte contemporânea na Educação Infantil. Pelo contrário, nossa intenção é a de inspirar os/as docentes para criarem instalações de jogo contextualizadas às suas demandas e realidades de trabalho. Por esse viés, entendemos que tais propostas podem ser uma oportunidade de mobilizar as crianças, tendo em vista a ampliação do repertório imagético e experiencial delas. Como mostramos no decorrer do artigo, as instalações de jogo, são promotoras de brincadeiras a partir das quais as crianças têm a possibilidade de desenvolver performances potencializadoras de seus modos de criação e expressão. Desse modo, convidamos agora você leitor/a a criar o seu inventário de obras e artistas para inspirar a criação de suas próprias propostas envolvendo instalações de jogo. Propostas de instalações de jogo abertas às intervenções, ressignificações e performances das crianças, por meio de experiências individuais e compartilhadas.

\section{REFERÊNCIAS}

ABAD MOLINA, J. Iniciativas de Educación Artística a través del Arte Contemporáneo para la Escuela Infantil (3-6 años). Madrid: UCM, 2008. 556. Tese - Departamento de Didáctica de la Expresión plástica, Facultad de Bellas Artes, Universidad Complutense de Madrid, Madrid, 2008.

ABAD MOLINA, J. RUIZ DE VELASCO GÁLVEZ, A. El juego simbólico. Buenos Aires: NoveducGraó, 2011.

ABAD MOLINA, J. RUIZ DE VELASCO GÁLVEZ, A. EI lugar del símbolo: El imaginario infantil en las instalaciones de juego. 046. Editorial Grao. Edição do Kindle. 2019.

BARBIERI, S. Interações: onde está a arte na infância? São Paulo: Blucher, 2012.

CAON, P.M. Jogos, performances e performatividades na escola: das experiências corporais à problematização de discursos. Cad. Cedes, Campinas, v. 37, n. I0I, p. 107-I30, jan.-abr., 2017.

Disponível em: <scielo.br/pdf/ccedes/v37n I0I/I678-7II0-ccedes-37-I0I-00107.pdf>. Acesso em: 25 de Jun. de 2021.

COCCHIARALE, F. Quem tem medo da arte contemporânea. Recife - Fundação Joaquim Nabuco, Editora Massangana, 2006.

COHEN, R. Performance como linguagem. Editora Perspectiva, I ${ }^{\text {a }}$ edição, 2002.

CUNHA, S.R.V. Uma arte de nosso tempo para as crianças de hoje. In: CUNHA, S. R.V.;

CARVALHO, R.S. (Org) A Arte Contemporânea e Educação Infantil. Porto Alegre: Mediação. 2017b. p. 9 - 26. 
As crianças e suas performances em contextos de instalações de jogo...

CUNHA, S.R.V. Questionamentos de uma professora de arte sobre o ensino de arte na contemporaneidade. In: Culturas da Imagem: Desafios para a arte e para a educação. Org. Raimundo Martins e Irene Tourinho. Santa Maria: Editora UFSM. 20I I. p. 99 - I23.

CUNHA, S.R.V. Cenários da educação infantil. Revista Educação e Realidade, Porto Alegre, 30(2): jul/dez 2005. p. 165 - I85. Disponível em: < seer.ufrgs.br/educacaoerealidade/article/view/I245 I/7365>. Acesso em: 25 de Jun. de 202I.

DELAVALD, C.C. A infância no encontro com a arte contemporânea: potencialidades para a educação. Dissertação (Mestrado) - Universidade Federal do Rio Grande do Sul, Faculdade de Educação, Programa de Pós-Graduação em Educação, Porto Alegre, 20I3. 130 f.

DÍAZ-OBREGÓN CRUZADO, R. Arte contemporáneo y educación artística: Los valores potencialmente educativos de la instalación. Madrid: UCM, 2003. 422. Tese - Departamento de Didáctica de la Expresión plástica, Facultad de Bellas Artes, Universidad Complutense de Madrid, Madrid, 2003.

DONADEL, B.D. Hélio Oiticica e o sentido da participação do público na arte brasileira dos anos 60: da Obra Aberta ao Exercício Experimental da Liberdade. Dissertação (Mestrado Programa de Pós-Graduação em História). Universidade Federal de Santa Catarina, Centro de Filosofia e Ciências Humanas. Florianópolis, Santa Catarina, 2010. $129 \mathrm{f}$.

FIANS, G. Entre crianças, personagens e monstros: uma etnografia de brincadeiras infantis. Rio de Janeiro: Ponteio, 2015.

FREITAS, M.G. NOTAS SOBRE O DESERTO: EXTENSÃO E TRANSBORDAMENTO COMO ARTICULADORES ESPAÇO-TEMPORAIS. Tese (Doutorado) - Universidade Federal do Rio Grande do Sul, Instituto de Artes, Programa de Pós-Graduação em Artes Visuais, 2016.

IAVELBERG, R. Arte, infância, formação docente e cultura na escola. In: CUNHA, S. R. V; CARVALHO, R. (Org). A Arte Contemporânea e Educação Infantil. Porto Alegre: Mediação, 2017. p. 27 - 36.

ICLE, G. Da performance na educação: perspectivas para a pesquisa e a prática. In: PEREIRA, Marcelo Andrade. Performance e educação: (des)territorializações pedagógicas. Santa Maria: ED. Da UFSM, 2013, p. 9 - 22.

LAPOLLA, P.; ARCE, M; A.; MUCCI, M. Experiencias artísticas con Instalaciones: trabajos interdisciplinarios de simbolización y juego en la escuela infantil. Buenos Aires: Noveduc, 2017.

MACHADO, M. A Criança é Performer. Revista Educação e Realidade, Porto Alegre, Brasil. vol. 35, núm. 2, maio-agosto, 2010a, p. II5-137. Disponível em:

<seer.ufrgs.br/educacaoerealidade/article/view/I I444>. Acesso em: 25 de Jun. de 202 I.

MACHADO, M. Merleau-Ponty \& a Educação. Belo Horizonte: Autêntica Editora, 20I0b.

(Coleção Pensadores \& Educação, 19).

MARQUEZ, R M. HÉLIO OITICICA: DESDOBRAMENTOS DO CORPO NO ESPAÇO. Revista

Vivência. ISSN 0104-3064. Natal, EdUFRN, v.33, 2009, p. 67-75. Disponível em:

<www.geografiaportatil.org/files/helio-oiticica.pdf>. Acesso em: 25 de Jun. de 2021.

Olhar de professor, Ponta Grossa, v. 24, p. I-24, e-17640.065, 2021.

Disponível em <https://revistas2.uepg.br/index.php/olhardeprofessor> 
NALINI, D. Construindo Campos de Experiências: Creche, Arte contemporânea e a poética das crianças de 0 a 3 anos. Tese (Doutorado - Programa de Pós-Graduação em Educação) Universidade de São Paulo, Faculdade de Educação, São Paulo: s.n., 20I5. 228 p.

NETO, E. Informações sobre o artista. In: ENCICLOPÉDIA Itaú Cultural de Arte e Cultura Brasileiras. São Paulo: Itaú Cultural, 2020. Disponível em:

<enciclopedia.itaucultural.org.br/pessoal I 848/ernesto-neto>. Acesso em: 06 de Jan. de 2020. Verbete da Enciclopédia.

OROFINO, K. Z. Crianças e Arte Contemporânea: experiências e interações. Tese (doutorado) - Universidade Federal de Santa Catarina, Centro de ciências da Educação, Programa de PósGraduação em Educação. Florianópolis, 2017. 381 p.

OSTETTO, L. E.; MELO, Maria Isabel. Na escola, na cidade, no museu: fazer e pensar artes visuais na educação infantil. Revista GEARTE, Porto Alegre, v. 6, n. 3, p. 497-5I3, set./dez. 20I9. Disponível em: <seer.ufrgs.br/gearte>. Acesso em: 06 de Mar. de 2021.

PONTES, B. “Eu sou essa! Eu sou esse!” Corpos, perspectivas e minúcias teatrais na pequena infância. Dissertação (mestrado) - Universidade Federal de Minas Gerais, Faculdade de Educação, Programa de Pós-Graduação em Educação. Belo Horizonte, 2016. 142 p.

SANTOS, N.S. Arquiteturas efêmeras de jogo na Educação Infantil: Crianças e Arte Contemporânea. Porto Alegre, 2018. 138p. Monografia (Trabalho de Conclusão de Curso) Licenciatura em Pedagogia, Faculdade de Educação, Universidade Federal do Rio Grande do Sul, Porto Alegre, 2018.

SANTOS, N. S.; CARVALHO, R. S. Arquiteturas efêmeras de jogo e Educação Infantil: diálogos com a Arte Contemporânea. Revista Apotheke, Santa Catarina, v.5, n.3, ano 5, dez. 2019, p. 25 - 42. Disponível em: <revistas.udesc.br/index.php/apotheke/article/view/l6/6l/IIIII > Acesso em: 25 de Jun. de 2021 .

SCHECHNER, R. Performance studies: an introduction. Routledge. 3rd ed. Edição Kindle. 2013.

SINGER, L. Espacios, territorios y entornos de aprendizaje: múltiples lenguajes para las infâncias: instalaciones y dispositivos lúdicos. Ciudad Autónoma de Buenos Aires: Centro de Publicaciones Educativas y Material Didáctico, 2019.

TILBURG, Merel van. Découvrir, récupérer, recycler, transformer: thèmes, objets et matériaux dans l'ouvre d'Ulla von Brandenburg. In: CHARPY, Manuel. DELAUNAY, Léonor. FERNANDEZ, Laure. GOURMEL, Yoann. TILBURG, Merel van. Ulla von Brandenburg «Le milieu est bleu» Palais de Tokyo. Editora Palais de Tokyo. 2020. p. 60-66.

VALLE, L. D. A potência edu(vo)cativa da arte contemporânea: desafios e possibilidades. Revista Digital do Laboratório de Artes Visuais, UFSM/RS, v. 12, p. 82, 2019. Disponível em: <periodicos.ufsm.br/revislav/article/view/37258>. Acesso em: 25 de Jun. de 2021.

VON BRANDENBURG, U. Informações sobre a artista. Disponível em: <palaisdetokyo.com/en/event/ulla-von-brandenburg-0> Acesso em: 04 de Mar de 2020.

Olhar de professor, Ponta Grossa, v. 24, p. I-24, e-17640.065, 2021. 
Recebido em: I5 de março de $202 \mathrm{I}$.

Versão corrigida recebida em: 18 de março de 2021

Aceito em: 18 de março de 2021 .

Publicado online em: 26 de junho de 2021.

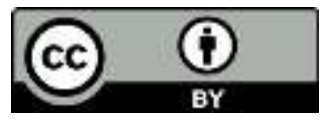

